\title{
Effect of Overactive bladder syndrome on female sexual function
}

\begin{abstract}
Soha A. Eladyed, Galal A. El-kholy, Soad A. Ramadan, Afaf M. Emam
Abstract: Female sexual function is Avery important and often neglected area of research. Therefore, the purpose og this study was to assess the relationship between overactive bladder syndrome and female sexual function. The study was conducted at Urological Outpatient clinic and Obstetrics and Gynecological clinic at Benha University Hospital. The design of this study was a descriptive research design. A purposive sample included 70 sexually active women diagnosed with overactive bladder syndrome were recruited in the study. Three instruments were utilized for data collection, interviewing questionnaire sheet, Female sexual function Index (FSFI) and Overactive Bladder Symptoms score (OABSS). The results of the study showed that there was highly statistical significant correlation between overactive bladder syndrome and female sexual function. Conclusion: highly statistical significant correlation was found between overactive bladder syndrome and female sexual function at $5 \%$ level of statisical significance. Therefore, it was recommended that this syudy should be conducted on alarge number of sample.
\end{abstract}

Key words: Female sexual function, women with overactive bladder syndrome.

\section{Introduction}

Sexuality is an important and integral part of every woman's life, and in fact female sexual dysfunction can lead to personal distress and anxiety. Under the term "female sexual dysfunction" is included a variety of disorders associated with components of sexual function such as sexual desire, arousal and orgasm and pain related to sexual intercourse as well (Castagna \& Montorsi and Salonia 2015).

Despite the importance of a healthy sex life to most people, research suggests that sexual dysfunction is common. Female sexual dysfunction (FSD) can occur at any stage of life, It may be lifelong or acquired; situationspecific or generalized; and mild, moderate, or severe based on the degree of distress it causes to the woman. The etiology is multifactorial ( Kingsberg, et al, 2017).

In general, factors that can contribute to its development may be psychogenic, physical and mixed. Each of these factors consists of individual components that influence the sexual response; However their precise impact in FSD development and progression is unknown (Holly, et al, 2016). Moreover, the effect of Overactive bladder syndrome on the development and progression of FSD has been poorly investigated. Overactive bladder (OAB) is defined as frequent urination with or without an urge of incontinence and it is usually associated with frequency and nocturia in the absence of infection or other pathological conditions. It is a common and distressing medical condition that can severely affect patient's quality of life (Gardikou , et al, 2013).

\section{Subjects and Method}

\section{Study design:}

A descriptive design was utilized for the conduction of this study.

\section{Setting:}

The study was conducted at Urological Outpatient clinic and Obstetrics and 
Gynecological clinic at Benha University Hospital.

\section{Subjects:}

-Sample Type: A purposive sample.

-Sample Size: all available women during time of data collection from the previous mentioned setting were included in the study $(\mathrm{n}=70)$.

\section{Inclusion criteria of the study were:}

Married, sexually active women, Diagnosed with overactive bladder syndrome and willing to participate in the study.

\section{Exclusion criteria of the study were:}

Pregnant and lactating women, Have medical disorders such as diabetes, uterus prolapsed and uterine inversion, take medication overactive bladder syndrome

\section{Instruments:}

Three instruments were used for collecting data:

Instrument one: An interviewing questionnaire Sheet: It was designed by the researcher after reviewing the related literature.

\section{Instrument two: Female Sexual} Function Index (FSFI), it was developed by Rosen 2000 to assess the key dimensions of sexual function in women. This questionnaire consists of 19 questions that assess sexual function over the past 4 weeks and yield domain scores in six areas: sexual desire, arousal, lubrication, orgasm, satisfaction, and pain (Filipa,etal,2017).

Instrument three: Overactive Bladder Symptoms (O.A.B): it was developed by Homma 2006: It is selfassessment questionnaire consisting of 4 questions (daytime frequency, nighttime frequency, urgency, and urge incontinence) assessing $\mathrm{OAB}$ symptoms. Women responded to each question about their bladder symptoms during the previous week. The OABSS provides an overall composite score, as well as individual scores.

\section{Results}

Table 1 describes the social characteristics of the studied women. It illustrated that the mean age of the studied women was $24.18 \pm 8.785$ and about $41.4 \%$ of them were more than 50 years. More than one quarter (28.6\%) of women had primary or preparatory education. Nearly two thirds $(61.4 \%)$ of them were housewives. In addition, more than half of the studied women lived in extended family and were from rural areas $(65.7 \%$ \& $54.3 \%)$ respectively.

Table 2 illustrates that more than one half $(55.7 \%)$ of the studied women were multigravida from 4-6 times with mean number $(3.80 \pm 1.098)$.More than two thirds $(67.1 \%)$ of them were multipara with mean number (2.97 \pm 0.833$)$. Less than three quarters (72.9\%) had normal delivery. Most of them , $(81.4 \% \& 70.0 \%)$ respectively had a history of abortion and complication during labor.

$\underline{\text { Table } 3}$ illustrates the studied women's sexual function index domains. The majority mean and stander deviation was the lubrication domain $(10.9714 \&$ 4.83037 respectively), while the minority was desire domain $(5.4000 \&$ 2.39202).

Table 4 demonstrates that, there was highly statistically significant relation between female sexual function and personal characteristics among the studied women

Table 5 reveals negative association, that interpreted the highly over active bladder symptoms was associated with low female sexual function. 
Table (1): Social characteristics of the studied women $(n=70)$.

\begin{tabular}{|l|l|l|}
\hline Variable & No & \% \\
\hline Age / years & 16 & 22.9 \\
\hline$<30$ & 25 & 35.7 \\
\hline $30-50$ & 29 & 41.4 \\
\hline$>50$ & $24.18 \pm 8.785$ \\
\hline Mean \pm SD & 18 & 25.7 \\
\hline Educational level & 20 & 28.6 \\
\hline Illiterate & 14 & 20.0 \\
\hline Primary or Preparatory & 18 & 25.7 \\
\hline Secondary & 38 \\
\hline University & 32 & 54.3 \\
\hline Residence & 32 & 45.7 \\
\hline Rural & \multicolumn{2}{|l|}{} \\
\hline Urban & 27 & 38.6 \\
\hline Employment & 43 & 61.4 \\
\hline Employed & 65.7 \\
\hline House wife & 46 & 34.3 \\
\hline Family type & 24 \\
\hline Extended & \multicolumn{1}{|l|}{} \\
\hline Nuclear
\end{tabular}

Table (2): Distribution of the studied women according to obstetrical characteristics $(n=70)$.

\begin{tabular}{|l|l|l|}
\hline Obstetrical characteristics & No & $\%$ \\
\hline Number of gravidity & 28 & 40.0 \\
\hline $1-3$ & 39 & 55.7 \\
\hline $4-6$ & 3 & 4.3 \\
\hline $7-9$ & $3.80 \pm 1.09$ & \multicolumn{2}{l|}{} \\
\hline Mean \pm SD & \multicolumn{2}{l|}{} \\
\hline Number of parity & 21 & 30.0 \\
\hline $1-3$ & 47 & 67.1 \\
\hline $4-6$ & 2 & 2.9 \\
\hline $7-9$ & $2.97 \pm 0.83$ & \\
\hline Mean \pm SD & 57 & 81.4 \\
\hline Previous abortion & 57 & 18.6 \\
\hline Yes & 13 & 72.9 \\
\hline No & \multicolumn{2}{l|}{} \\
\hline Mode of delivery & 51 & 27.1 \\
\hline Vaginal & 19 & 70.0 \\
\hline Cesarean section & 49 & 30.0 \\
\hline Complication during labor & 21 & \\
\hline Yes & \multicolumn{2}{|l|}{} \\
\hline No &
\end{tabular}

Table (3): Distribution of the studied women to their Female Sexual Function Index Score.

\begin{tabular}{|c|c|c|c|c|}
\hline Item & Minimum & Maximum & \% & Mean \pm SD \\
\hline Desire & 2.00 & 10.00 & 54 & $5.40 \pm 2.39$ \\
\hline Arousal & 4 & 20 & 53.8 & $10.76 \pm 4.76$ \\
\hline Lubrication & 4.00 & 20.00 & 54.85 & $10.97 \pm 4.83$ \\
\hline Orgasm & 3.00 & 15.00 & 54.48 & $8.17 \pm 3.43$ \\
\hline Satisfaction & 3.00 & 15.00 & 53.4 & $8.01 \pm 3.56$ \\
\hline Pain & 3.00 & 15.00 & 54.06 & $8.11 \pm 3.60$ \\
\hline Total & 19.00 & 95.00 & 54.12 & $51.43 \pm 22.079$ \\
\hline
\end{tabular}

Table (4): Relation between Total Female sexual Function Index score and Sociodemographic characteristics' of the studied women $(n=70)$. 


\begin{tabular}{|c|c|c|c|c|}
\hline \multirow{2}{*}{ Variable } & \multirow{2}{*}{ Mean \pm SD } & \multicolumn{2}{|c|}{ Statistical test } & \multirow{2}{*}{$P$ value } \\
\hline & & F test & T test & \\
\hline Age / years & & \multirow{4}{*}{11.91} & & \multirow{4}{*}{$<0.001 * *$} \\
\hline$<30$ & $71.43 \pm 22.06$ & & & \\
\hline $30-50$ & $48.84 \pm 19.04$ & & & \\
\hline$>50$ & $42.62 \pm 17.73$ & & & \\
\hline \multicolumn{2}{|l|}{ Education Level } & \multirow{5}{*}{11.09} & & \multirow{5}{*}{$<0.001 * *$} \\
\hline Illiterate & $33.38 \pm 13.22$ & & & \\
\hline Primary or Preparatory & $47.60 \pm 17.72$ & & & \\
\hline Secondary & $62.00 \pm 23.68$ & & & \\
\hline University & $65.50 \pm 18.98$ & & & \\
\hline \multicolumn{2}{|l|}{ Residence } & & \multirow{3}{*}{2.88} & \multirow{3}{*}{$<0.001 * *$} \\
\hline Rural & $44.73 \pm 20.07$ & & & \\
\hline Urban & $59.37 \pm 22.00$ & & & \\
\hline \multicolumn{2}{|l|}{ Employment } & & \multirow{3}{*}{3.73} & \multirow{3}{*}{$<0.001 * *$} \\
\hline Employed & $62.85 \pm 20.27$ & & & \\
\hline House wife & $44.25 \pm 20.24$ & & & \\
\hline \multicolumn{2}{|l|}{ Family type } & & \multirow{3}{*}{3.39} & \multirow{3}{*}{$<0.001 * *$} \\
\hline Extended & $45.45 \pm 20.80$ & & & \\
\hline Nuclear & $62.87 \pm 20.18$ & & & \\
\hline
\end{tabular}

NB: High Significant relation at level of $(\mathrm{P}$ - value $<0.001)$.

Table (5): Correlation between total sexual health and total score of symptoms of overactive bladder of the studied women $(n=70)$.

\begin{tabular}{|c|c|c|}
\hline \multirow{2}{*}{ Variables } & \multicolumn{2}{|c|}{ Overactive bladder symptoms } \\
\cline { 2 - 3 } & $\mathbf{r}$ & P value \\
\hline Sexual function & -0.205 & 0.089 \\
\hline
\end{tabular}

\section{Discussion}

Overactive bladder syndrome is a common and annoying complication worldwide. OAB has abroad adverse impact on female sexuality in sexually active women. Overactive bladder women have much greater prevalence of sexual dysfunction than those who are not. Many studies reported that sexual dysfunction is the major, albeit multifaceted, issue that negatively impact on women quality of life (Corcos, et al, 2017).

The present study aimed to assess the effect of overactive bladder syndrome on female sexual function. The aim was achieved through answering the research question of the present study which was: Is the overactive bladder syndrome affect women's sexual function?
Regarding women's demographic characteristics, the finding of the present study revealed that less than half of the studied women aged more than 50 years with mean age of $(24.18 \pm 8.785)$ year. More than one quarter had primary or preparatory education, nearly two thirds were housewives. In addition, more than half of the studied women live in extended family and from rural areas. This could be due to elderly women differ from their younger counterparts by the presence of several physiologic changes in the urinary tract, as well as the presence of concomitant morbidity and polypharmacy and Pelvic floor strength is reduced and levatorani is increased in older women. Moreover, increasing the level of education can improve of overactive bladder syndrome and help women to seek medical advice and 
treatment and women from rural areas most times derived from medical services.

This findings were supported by Muzaffer et al, (2018) who reported that overactive bladder prevalence increases with age and reaches a maximal level around the age of 50, The mean age of the subjects was $26.47 \pm 4.8$ years, $23.1 \%$ of the study subjects had concluded primary education and the majority of their studied women were housewives.

On the other hand Naser Eldeen (2011) disagree with the current findings, who revealed that the mean age was estimated to be $39.3 \pm 10.6$ years, and the prevalence of overactive bladder increases in middle age women ranges from 41-45 years and there were no significant association between the family status and the total overactive bladder scores.

As regards mean score of female sexual function index, the results of the present study revealed that the mean and SD was $(51.43 \pm 22.079)$ with the majority mean and SD was the lubrication domain (10.97 \pm 4.83), while the minority was desire domain $(5.40 \pm$ 2.39) and showed impaired function in all domains(desire, arousal, lubrication, orgasm, satisfaction, and pain) but arousal was the most sexual problem.

This finding was supported by Fecsm, et al, (2014) Who noticed that mean and SD of the total FSFI score was $54.53 \pm$ 22.68 The majority mean and SD was the lubrication domain (10.08 \pm 4.43$)$, while the minority was desire domain (4.08 \pm 1.43$)$.

On the other hand, this finding was in contrary with El Atrash et al, (2014) who found that the majority of the subject study reported low sexual desire. Also, contradicated by Mostafa et al, (2017) who found that pain was the most common sexual problem among
Egyptian women suffering from urinary tract disorder.

As regards age of the studied women, the results of the present study revealed that female sexual dysfunction was more likely to be in older age more than 50 years. The impact of age on women's sexual function and sexuality could be associated with premenopausal and menopausal status, which is followed by a significant decrease in estrogen levels, which is associated with a weakening sex drive. Also, older women are more likely to have vaginal atrophy and more prone to suffer from sexual dysfunctions as a result of vaginal dryness and dyspareunia

This finding was supported by Anis, et al,(2014) who found that more than one half of the studied sample were in older age had female sexual dysfunction.

On the other hand, this finding was in converse with Sungur,et al,(2014) who found that the prevalence of low sexual function associated with distress in middle-age women

In relation to educational level, the results of the present study revealed that the majority of the studied women were illiterate with mean and SD (33.38 \pm 13.22$)$, housewife, lived in extended family and from rural areas. This results may be due to women who were highly educated (university and secondary school education) done more visits to outpatient clinics and insisted on getting cured and had normal life than do the women with less education.

This finding was in the same line with Asadi, et al, (2014) who found that more than two thirds of the studied subjects with female sexual dysfunction were illiterate with mean and SD (34.23 \pm 7.62$)$, housewife, lived in extended family and from rural areas.

On the other hand Joseph \& Rees (2013) disagree with the present study, and 
found that more than half of the studied women with female sexual dysfunction had secondary education with mean and SD (22.23 \pm 5.62$)$, working and live in nuclear family.

Regarding the characteristics of the obstetric history of the studied women the present study revealed that more than half were multiparous, delivered vaginally, had history of abortion and complications during labor.

This finding was supported by Manal \& Mahmoud (2016) who found the majority of the studied subjects were multiparous, had obstructed labor and experienced complications.

Concerning relation between total female sexual function index and total score of symptoms of overactive bladder symptoms, the present study findings revealed a significant negative association, this finding may interpret that the highly over active bladder symptoms was associated with low sexual function.

This finding was supported by Melotti, et al, (2017) who revealed that women with scores indicating severe overactive bladder had worse sexual function, mainly in the arousal, lubrication, orgasm, pain, and total domains.

\section{References}

Abrams, P., Kelleher C., Staskin D., Kay R., Martan A., Mincik, I.(2017): Combination treatment with mirabegron and solifenacin in patients with overactive bladder: exploratory responder analyses of efficacy and evaluation of patientreported outcomes from a randomized, double-blind, factorial, dose-ranging, Phase II study (SYMPHONY);World J Urol 8(4): 99-100.

Abrams, P., \& paul. (2011): Fourth International Consultation on
Incontinence Recommendations of the International Scientific Committee: Evaluation and treatment of urinary incontinence, pelvic organ prolapse, and fecal incontinence. Neurourology and Urodynamics 29, 213-240.

Afiyanti, Y., Rachmawati, I. N., \& Milanti, A. (2016): Evaluating Sexual Nursing Care Intervention for Reducing Sexual Dysfunction in Indonesian Cervical Cancer Survivors. Asia-Pacific Journal of Oncology Nursing, 3(3), 266-271. http://doi.org/ HYPERLINK "http://doi.org/10.4103/2347-

5625.189812"10.4103 HYPERLINK "http://doi.org/10.4103/23475625.189812"/ HYPERLINK "http://doi.org/10.4103/23475625.189812"2347-5625.189812

Ambler, Y., Burri, A., Greven, C., Leupi, M.(2012): A multivariate twin study of female sexual dysfunction. J Sex Med ;9:267181.

Amico, F., \& Donita, T.(2016): Prevention and management of pelvic organ. Sep 4 2016; 6: 77.

Amidu, N., Owiredu, W., Woode, E., Addai-Mensah, O., Quaye, L., Alhassan, A., Tagoe, EA .(2016) :Incidence of sexual dysfunction: a prospective survey in Ghanaian females. Reprod Biol Endocrino;1A. El-Nashar, T. Mostafa , T.A. El-Naser, A. Farouk.( 2017):Sexual side effects of female genital mutilation/cutting may be type dependent: a hospital-based study KAJOG Kasr Al-Aini, J. Obstet. Gynecol. 3(5) 89-99.

A.M. Mostafa. (2017): Prevalence and patterns of female sexual dysfunction among overweight and obese premenopausal women in 
Upper Egypt; a cross sectional study, Middle East Fertil Soc J; 4(7):22-26. $\quad$ http://dx. doi.org/10.1016/j.mefs.2017.08.00 $\underline{6}$

Andera, K., Schreiner, L., Santos, T., Knorst, M. (2014): Randomised trial of transcutaneous tibial nerve stimulation to treat urge urinary incontinence in older women. Int Urogynecol J; 21:1065-1070.

Angelini, D., Stewart, S., Luis F.; El Dib, Regina; Gameiro, Monica O., Kapoor, Anil, Amaro, Joao, L. (2016): "Electrical stimulation with non-implanted electrodes for overactive bladder in adults". Sep; 55(3):200-204.

Atherly, A., \& Thorpe, K.E. (2015): Analysis of the treatment effect of Healthway's Medicare health support phase 1 pilot on Medicare costs. Population Health Management ; 14:23-28.

Avasthi, Ajit, Sandeep Grover, and T S Sathyanarayana Rao. (2017): "Clinical Practice Guidelines for Management of Sexual Dysfunction." Indian Journal of Psychiatry 49: B91-B115. PMC. Web. 9 Feb. 2018.

Avbin, A., \& Peretez, S. (2015): Clinical Practice Guidelines for Management of Sexual Dysfunction. Indian Journal of Psychiatry,59 (Suppl 1), S91S115. http://doi.org/ HYPERLINK "http://doi.org/10.4103/00195545.196977"10.4103

\section{HYPERLINK}

"http://doi.org/10.4103/00195545.196977"/ HYPERLINK

"http://doi.org/10.4103/0019-

5545.196977"0019-5545.196977

Avşar Dallosso HM, McGrother CW, Matthews RJ, Donaldson MM Leicestershire MRC(2015): Incontinence Study Group. The association of diet and other lifestyle factors with overactive bladder and stress incontinence: a longitudinal study in women. BJU Int.;92:69-77.

Bajramovic, L. Sattar, S.A., Tetro J, Springthorpe VS. (2014): Impact of changing societal trends on the spread of infections in American and Canadian homes. Am J Infect Control;27:S4-21.

Balon, R., Clayton, A.H., Beji, N.K., Ozbas, A. (2014):Female sexual interest/arousal disorder: a diagnosis out of thin air. Arch Sex Behav ;43:1227-9.

Barbara Liord, Bhide, A.A., Digesu, G.A., Fernando, R., Khullar, V. (2012):LUse of mirabegron in treating overactive bladder. Int Urogynecol J. Mar 13.

Bargiota, L., Nusbaum, G.,Ahlers, C.J., Schaefer, G.A., Mundt, I.A.(2011): How unusual are the contents of paraphilias? Paraphilia-associated sexual arousal patterns in a communitybased sample of men. J Sex

Med ;8:1362-70. 